\title{
GASTOS PÚBLICOS COM DIÁRIAS E PASSAGENS UM ESTUDO DE CASO SOBRE PROCEDIMENTOS DE CONTROLE INTERNO NO ÂMBITO MUNICIPAL
}

\author{
PUBLIC EXPENSES WITH DAILY AND PASSAGES \\ A CASE STUDY ON INTERNAL CONTROL \\ PROCEDURES AT THE MUNICIPAL LEVEL
}

Simone Müller Moreira ${ }^{1}$

Cristiano Sausen Soares ${ }^{2}$

1

Graduação em

Contabilidade e Pós

Graduação lato-

sensu em Auditoria

e Controladoria pela

Universidade Franciscana.

Servidora pública

municipal da Prefeitura

de Santa Maria/Rs.

2

Doutorando em

Contabilidade (PPGC/UFSC);

Mestre em Administração (PPGA/UFSM); Especialista em RH e Marketing (FAMEs), Bacharel em Contabilidade (UFN) e Arquivologia (UFSM), Prof. dos Cursos de Ciências Contábeis e Administração uFN e Contador na Prefeitura de Santa Maria/Rs.
Resumo: A concessão de diárias e passagens no serviço público deve respeitar normas de finanças públicas e a Teoria Institucional pode auxiliar no entendimento de procedimentos para controle e concessão desses gastos. Assim, este estudo tem por objetivo analisar como ocorre o processo de concessão e controle de gastos com diárias e passagens no âmbito municipal. A pesquisa foi realizada no município de Santa Maria/Rs, a partir dos dados divulgados no portal de transparência, pesquisa documental e entrevista. Os resultados denotam a existência de legislação específica, identificando-se que o controle interno é efetivo. A institucionalização de práticas para a concessão de diárias e passagens está constituída em normativas que atendem as prescrições legais. Na visão do orçamento, constatou-se que os valores gastos apresentam baixa representatividade frente à receita. Foram comparadas as despesas entre os cinco municípios com maior população do estado gaúcho, verificando que em Santa Maria/Rs, no ano de 2014, o valor gasto com diárias e passagens foi de $\mathrm{R} \$ 2,34$ por habitante. Por fim, entende-se que os resultados podem contribuir com os entes públicos municipais, servidores, sociedade e demais entidades na fiscalização e instrumentalização de procedimentos realizados na concessão e controle de gastos com diárias e passagens.

palavras-chave: Despesa Pública; Serviço Público; Diárias e Passagens.

ABSTRACT: The concession of diaries and passages in the public service must comply with public finance norms and the Institutional Theory can help in the understanding of procedures to control and grant these expenses. Thus, this study aims to analyze how the process of concession and control of expenses with daily and passages in the municipal scope occurs. The research was carried out in the municipality of Santa Maria/Rs, based on the data disclosed in the portal of transparency, documentary research and interview. The results indicate the existence of specific legislation, identifying that internal control is effective. The institutionalization of practices for the concession of daily and passages is constituted in regulations that meet the legal prescriptions. In the view of the budget, it was verified that the amounts spent have low representativeness compared to the revenue. Expenditures between the five cities with the largest population in the state of Rio Grande do Sul were compared, and in Santa Maria/Rs, in 2014, the amount spent on daily and passages was R \$ 2.34 per inhabitant. Finally, it is understood that the results can contribute to municipal public entities, civil servants, society and other entities in the inspection and instrumentalization of procedures performed in the concession and control of expenses with daily and passages. KEYWORDs: Public Expenditure; Public service; Daily and tickets 


\section{INTRODUÇÃO}

A sociedade brasileira vem presenciando denúncias de corrupção e desvios de recursos públicos, exigindo das entidades governamentais maiores controles e fiscalização na execução da despesa pública. Neste cenário, os procedimentos de contabilidade voltada ao setor público apresentam instrumentos legais que auxiliam no controle da despesa, visando à qualidade do gasto público (NOvAEs; LASSO; MAINARDES, 2016). Dentre os principais instrumentos voltados ao controle de gastos, citam-se a Lei Complementar (LC) n $n^{0}$ 101/2000, conhecida como Lei de Responsabilidade Fiscal (LRF), a LC nํ131/2009, chamada de Lei de Transparência e a Lei n⿳ํㅜ 12.527/2011, intitulada Lei de Acesso a Informação (LAI).

Denúncias do tipo "farra das diárias" evidenciam possível mau uso de diárias e passagens, indicando que algumas concessões são utilizadas em prol de interesses particulares. Como exemplo, Grizotti (2006) apresentou o caso que apontava alguns vereadores do sul do Brasil, em momentos de lazer, quando deveriam frequentar cursos de capacitação, cujos deslocamentos e estadias foram financiados com recursos públicos. Por sua vez, Samora (2014) constatou que a esposa de um ex-governador viajava para São Paulo e Rio de Janeiro, com recursos públicos, porém o real motivo da viagem era visitar os filhos que lá moravam. Esses casos e outros reportados (MARTINS, 2009) demonstram que o dinheiro público, muitas vezes, é utilizado sem retorno à população. Desse modo, a organização pública precisa desenvolver formas de aprimorar seus processos e otimizar o uso dos recursos, que muitas vezes são escassos, cumprindo a legislação e seus objetivos.

Nesse sentido, a participação do cidadão na fiscalização das atividades exercidas por agentes públicos é essencial para a consolidação da democracia, mas o próprio ente deve fornecer as informações necessárias para tal controle (BRASIL, 2011). Contudo, para que o ente público cumpra seu papel é necessária a atuação de um órgão de Controle Interno eficaz. Peter e Machado (2008) definem o controle interno como um órgão da entidade pública que realiza um conjunto de atividades para assegurar que os objetivos estipulados pela gestão sejam alcançados, de forma confiável e concreta, sendo utilizado como apoio ao sistema contábil, minimizando riscos e atribuindo efetividade, tempestividade e confiabilidade às informações. Assim, a implantação do Controle Interno nos entes públicos, em especial nos municípios, apresenta-se como uma oportunidade para institucionalizar instrumentos de gestão pública e gerar informações que auxiliem no processo decisório (MARÇOLA, 2011).

Os municípios são entes públicos que detêm a responsabilidade de executar grande parte dos serviços demandados pela comunidade, com seus orçamentos cada vez menores, frente às mais diversas obrigações (SOARES; FLORES; CORONEL, 2014). Entretanto, determinadas despesas são essenciais para o cumprimento dos serviços públicos, dentre as quais podem ser citadas as despesas com diárias e passa- 
gens, porém, cada município deve estabelecer normativas para concessão e controle desses gastos, evitando irregularidades. Assim, o município de Santa Maria/Rs, considerado um dos mais transparentes do estado gaúcho, de acordo com o Tribunal de Contas Estadual (тсЕ/ RS), apresenta instrumentos institucionalizados para concessão de diárias e passagens, além de procedimentos e legislação específica para fiscalização e controle dessa despesa, em atendimento às normativas de auditoria pública.

As despesas com diárias são gastos orçamentários que, conforme a Controladoria Geral da União (CGU, 2012), destinam-se a indenizar o servidor público pelas despesas com hospedagem, alimentação e locomoção urbana, durante seu deslocamento fora do local de lotação. Por sua vez, os gastos com passagens são despesas que podem ser tanto rodoviárias quanto aéreas, conforme a necessidade do usuário. Tendo em vista que a despesa pública com diárias e passagens é constantemente alvo de fiscalização dos Tribunais de Contas Estaduais, retrata-se a relevância e necessidade do controle desses gastos.

Diante do exposto, a presente pesquisa busca responder a seguinte questão: Como ocorre o processo de concessão e controle de gastos com diárias e passagens em um ente público municipal? Para tanto, o objetivo desta pesquisa é analisar os procedimentos de concessão e controle das despesas de diárias e passagens no município de Santa Maria/Rs.

A justificativa do estudo se deve ao fato de diárias e passagens serem gastos que consomem recursos públicos, frente a outras necessidades mais urgentes da sociedade, sendo um tema pouco explorado em estudos empíricos. Neste sentido, Devarajan, Swaroop e Zou (1996) indicam que a aplicação dos recursos no setor público deve privilegiar alocações mais produtivas em detrimento de outras que não tragam benefícios à sociedade. Assim, percebe-se a importância de estudos que tratam da qualidade do gasto público, visando a eficiência e o controle, além de trazer a discussão elementos teóricos que possam auxiliar na sua análise.

Dessa forma, a presente pesquisa está estruturada em 4 seções, além desta introdução. A base teórica é apresentada na seção seguinte, enquanto a terceira seção mostra a metodologia utilizada no estudo. A quarta seção analisa os resultados e, por fim, a quinta seção apresenta as considerações finais, seguidas das referências utilizadas no estudo.

\section{REFERENCIAL TEÓRICO}

\section{OS SERVIÇOS PÚBLICOS E AS FINANÇAS PÚBLICAS}

As entidades públicas existem para prestar serviços públicos, diretos e indiretos, no intuito de satisfazer as necessidades demandadas pela sociedade (ANDRADE, 2012). Neste sentido, a Teoria de Finanças Públicas explica a existência do Estado através da necessidade de guiar, corrigir e complementar as funções econômicas que o mercado não 
consegue realizar sozinho (GIAmbiagr; ALEM, 2011). Para tanto, as ações dos governos se fazem a partir de políticas (monetária, econômica e fiscal), englobando três funções básicas: alocativa, distributiva e estabilizadora (ALBUQUeRquE; MEDEIROS; FEIJó, 2008). Desta forma, as obrigações dos entes públicos e as normas de finanças públicas devem ser consideradas quando são definidas as ações e os objetivos da entidade, sendo necessário o planejamento, a execução e a prestação de contas relativas aos recursos arrecadados e suas aplicações em despesas públicas.

A despesa pública pode ser analisada sob duas óticas: patrimonial e orçamentária (ANDRADE, 2012). Segundo o Manual de Contabilidade Aplicado ao Setor Público (MCASP, 2017), a despesa pública, sob a ótica patrimonial, é analisada como Variação Patrimonial Diminutiva (VPD), pois se refere à aplicação de um recurso que diminui o Patrimônio da entidade. Sob o enfoque orçamentário, a despesa pública é considerada um dispêndio de recurso governamental utilizado para quitar obrigações com terceiros ou para manter e fazer funcionar todos os serviços prestados à comunidade, dependendo de autorização legislativa para ocorrer, conforme a Lei Orçamentária Anual (LOA). Ainda, a despesa pública deve servir para financiar a construção de obras que são indispensáveis ao bom andamento da cidade, como o asfaltamento de ruas, e também para proporcionar melhorias necessárias ao bem estar da população, com o intuito de atender seus anseios sociais, como por exemplo, a construção ou reforma de creches, escolas e postos de saúde.

Para Kohama (2000) a despesa pública se constitui de valores aprovados na lei orçamentária a serem utilizados nos serviços públicos ou aumentos patrimoniais, quitação da dívida pública ou outros gastos extraorçamentários. Por despesas orçamentárias entende-se aquelas que fazem parte da LOA, enquanto as despesas que não integrantes são consideradas extraorçamentárias (SILvA, 2004). A Portaria Interministerial (PI) $\mathrm{n}^{\mathrm{o}} 163$ de 04 de maio de 2001 classifica a despesa orçamentária de acordo com a Categoria Econômica, Natureza da Despesa, Modalidade de Aplicação e Elemento de Despesa.

A classificação da despesa, conforme a Categoria Econômica subdivide-se em despesas correntes e de capital. Slomski (2008) estabelece como despesa corrente toda aquela que não contribui diretamente para a formação ou aquisição de um bem de capital e se relaciona ao consumo do governo. Por outro lado, a despesa de capital representa os investimentos e contribuem diretamente para a formação ou aquisição de um bem de capital.

Conforme Slomski (2008), os grupos de Natureza de Despesa são formados por elementos de despesas que possuem as mesmas características quanto ao objeto do gasto. Observa-se que o grupo "outras despesas correntes" engloba despesas referentes à aquisição de material de consumo, pagamento de diárias, contribuições, auxílio alimentação e transporte, além de outras despesas não classificadas nos demais grupos de natureza corrente. 
Por sua vez, a classificação do Elemento da Despesa tem por finalidade identificar os objetos de gasto (SLOMSKI, 2008), tais como vencimentos e vantagens fixas, juros, diárias, material de consumo, serviços de terceiros prestados sob qualquer forma, subvenções sociais, obras e instalações, equipamentos e material permanente, auxílios, amortização e outros de que a administração pública se serve para a consecução de seus fins.

Para assegurar a eficiência dos gastos, as ações relacionadas aos recursos públicos estão sujeitas a fiscalização e controle, tanto internos quanto externos (PETER; MACHADO, 2008). No entanto, o controle interno é essencial à entidade pública para que a mesma possa atingir seus objetivos (SILVA; GOMES; ARAUJo, 2014). Neste sentido, a prestação de contas pode ser considerada uma forma de controle, pois por meio dela os gestores devem comprovar como aplicaram os recursos públicos.

Nessa linha, os recursos empregados pelos gestores públicos, com o intuito de atender aos programas e/ou atividades de governo, bem como aqueles destinados a manutenção da máquina pública serão alvo de controle interno e externo (MARçolA, 2011). Como exemplo, têm-se os recursos destinados à construção de estradas, escolas, creches, como também os utilizados para custear diárias e passagens. No entanto, estas últimas são constantemente visadas pela sociedade em geral no sentido de verificar a função de seu uso em prol do atendimento de fins específicos com reflexos à população.

O controle interno pode ser entendido como o conjunto de atividades, planos, métodos e procedimentos interligados e utilizados cotidianamente com o intuito de assegurar que os objetivos dos órgãos e entidades pertencentes à administração sejam atingidos de forma confiável e concreta. Atuando em conformidade com a norma, busca evidenciar possíveis desvios na execução das atividades, para que após descobertos possam ser corrigidos para não prejudicar as ações desenvolvidas pela administração pública (вотеLHO, 2005).

As diárias e passagens são gastos realizados para atender ao serviço público, devido à necessidade de um constante aperfeiçoamento de servidores, bem como no desenvolvimento de ações e programas relacionados às políticas públicas que necessitam de deslocamento de pessoal, com intuito de trazer benefícios à sociedade, podendo ser citado o transporte de pacientes da saúde para outras cidades. Assim, conceitua-se diária como a "cobertura de despesas de alimentação, pousada e locomoção urbana, com o servidor público estatutário ou celetista que se desloca da sua sede em objeto de serviço, em caráter eventual ou transitório" (CARVAlHo, 2007, p.312). Ainda, segundo o autor, os gastos com passagens dizem respeito às despesas com aquisição de passagens, sejam elas aéreas, terrestres, fluviais ou marítimas, bem como taxas de embarque, seguros, fretamento, pedágios, locação ou uso de veículos para transporte de pessoas e suas bagagens, desde que a viagem atenda ao interesse público. 
Raupp (2011) alerta que os gastos públicos com diárias e passagens são classificados como custos diretos, relacionados às atividades desenvolvidas nos respectivos centros de custos onde os servidores beneficiários estão lotados. Em outras palavras, diárias e passagens são despesas que o governo tem com seus agentes, quando os mesmos viajam a interesse da administração, incluindo-se a participação em cursos e treinamentos, dentre outros motivos. Ainda, esses gastos são considerados como Variações Patrimoniais Diminutivas Quantitativas (VPDQ), pois são fatos que diminuem o patrimônio líquido da organização pública, pela aplicação do recurso.

Segundo a CGU (2012), esse tipo de despesa deve ser utilizado com cautela, pois tanto os gestores quanto os servidores devem observar os princípios da economicidade, da impessoalidade, da moralidade, da eficiência e, principalmente, o princípio da motivação dos gastos, evitando a execução de despesas em atividades que não sejam de interesse público. Deste modo, o controle interno deve verificar se os procedimentos de concessão de diárias e passagens foram realizados de maneira correta, ou seja, de acordo com o orçamento total, em termos de valor e forma de concessão (JUNIOR; JENKINS; ZANIN; DE ALMEIDA, 2015).

\section{A TEORIA INSTITUCIONAL}

Conforme a corrente epistemológica da racionalidade limitada, a abordagem institucional afirma que grande parte das ações realizadas pelos indivíduos não resultam de lógicas cognitivas, mas de procedimentos usualmente aceitos como corretos. Neste sentido, no campo das organizações, desenvolveu-se a Teoria Institucional seguindo os postulados de Meyer e Rowan (1977) e DiMaggio e Powell (1983), com o objetivo de analisar as formas como os procedimentos e regras são incorporados às organizações e sua legitimidade frente ao ambiente externo e interno. Deste modo, considera-se que os atores seguem padrões socialmente construídos e compartilhados e que mecanismos institucionais moldam seu comportamento (DIMAGGIO; POWELL, 1983).

O ponto central da Teoria Institucional baseia-se no isomorfismo como processo para busca da legitimidade, sendo considerada uma ferramenta para compreender as políticas, processos e rituais que permeiam a vida das organizações (Dimaggio; Powell, 1983). Segundo os autores, há dois tipos de isomorfismo: o competitivo e o institucional. O Isomorfismo competitivo é um sistema racional que enfatiza a competição de mercado, onde as organizações imitam produtos, procedimentos e serviços, reduzindo as diferenças entre si no processo de competição; enquanto o isomorfismo institucional serve para entender as políticas internas existentes em organizações que competem entre si pela busca da legitimidade institucional, com foco nos objetivos sociais e econômicos, como ocorre com as organizações do setor público.

Considerando a legitimidade como um elemento da Teoria Institucional, Meyer e Scott (1983) definiram legitimidade organizacional como o grau de suporte cultural de uma organização. No en- 
tanto, Ruef e Scott (1998) complementam essa definição com outros elementos, conceituando legitimidade como uma condição que reflete o alinhamento cultural, o suporte normativo e sua consonância com regras e leis relevantes. Para Scott (1995), assumir uma perspectiva institucional no contexto organizacional é enfatizar a importância dos aspectos psicológicos, sociais e políticos no estudo das organizações, deslocando o foco para os sistemas de conhecimentos, crenças e regras que estruturam e permitem o funcionamento das organizações quanto aos aspectos regulatórios, normativos e cognitivos.

Na concepção regulatória das organizações, seguida principalmente por economistas e cientistas políticos, tem-se o foco na criação de regras e mecanismos de supervisão, incluindo o estudo das relações contratuais e governança, referenciados na Teoria da Agência e Teoria dos Custos de Transação. Nessa vertente teórica, as estruturas são consideradas as principais portadoras das regras institucionais. Em relação aos elementos normativos, quando considerados, são tratados como condições ambientais que afetam o projeto institucional (sсотT, 1995). Portanto, crenças morais e obrigações instituídas enfatizam a abordagem normativa das instituições, sendo o comportamento orientado pela função a ser desempenhado em determinadas situações sociais. Assim, normas e valores coletivos influenciam nas escolhas individuais e os critérios de adequação sofrem pressões normativas, em detrimento da otimização de resultados. Na perspectiva cognitiva das instituições, trazida pelo movimento neoinstitucional, as características dos atores envolvidos são definidas por normas culturais, sendo encontrada tal abordagem nos estudos da psicologia social, antropologia, ciência política e sociologia. As instituições, nesta perspectiva, não se enquadram como coleções de normas, mas sistemas de conhecimento que controlam o comportamento e as concepções de mundo dos atores e suas ações (scotT, 1995).

Os componentes regulatório, normativo e cognitivo originam os mecanismos isomórficos para avaliação da legitimidade e controle, destacando-se o coercitivo, normativo e mimético, respectivamente (DIMAGGiO; POWELL, 1983; RUEF; SCOTT, 1998). O mecanismo pelo qual as organizações se adaptam às pressões do ambiente regulatório é denominado isomorfismo coercitivo, resultado de pressões formais e informais exercidas sobre uma organização por outras, as quais ela dependa, e por expectativas culturais da sociedade na qual está inserida (DIMAGGIO; POWELL, 1983). Já as pressões normativas originadas das lutas coletivas de profissionais, consideradas como uma das principais fontes de isomorfismo normativo definem condições e métodos de trabalho e assim estabelecem uma base de legitimidade aos seus praticantes (DimagGio; Powell, 1983). Por fim, o componente cognitivo origina o mecanismo mimético, considerando as incertezas do ambiente externo e interno, podendo ser relacionado aos movimentos de empregados entre as organizações, pela atuação de empresas de consultoria ou associações empresariais. 
Meyer e Rowan (1977) propõem que estruturas formais das organizações podem surgir a partir de um contexto onde a estrutura de controle e a coordenação de atividades permite a obtenção de maior eficiência, a partir de uma rede de relacionamentos e interações sociais em um contexto altamente institucionalizado. Entretanto, destaca-se que não há tipos polarizados, mas um continuum onde as organizações se situam, devido às pressões por controles de resultados, onde o sucesso depende da estabilidade adquirida por meio do isomorfismo e padrões institucionalizados.

\section{ASPECTOS METODOLÓGICOS}

Este estudo classifica-se quanto ao problema como qualitativo. Conforme Creswell (2010) é o tipo de pesquisa que envolve as questões e procedimentos que emergem dos dados coletados no ambiente e sua análise é construída a partir das particularidades, cuja interpretação é realizada pelo pesquisador acerca do significado dos dados. Assim, fez-se contato direto com o ente público pesquisado, sendo necessária a inserção no ambiente onde acontece o Processo de Concessão de Diárias e Passagens (PCDP). Além disso, foi verificada a representatividade da despesa em relação ao orçamento, no ano de 2014, traçando seu comportamento e comparando com outros municípios, quanto aos gastos.

Quanto aos objetivos, a pesquisa se enquadra como descritiva. Gil (2010) considera a pesquisa descritiva como aquela que tem a finalidade de descrever as características de determinado assunto, estabelecendo interações entre variáveis. Neste caso, a pesquisa é descritiva porque elenca as etapas do PCDP, considerando ainda o papel do controle interno acerca da execução dessas despesas.

Do ponto de vista dos procedimentos técnicos, utilizou-se da pesquisa documental e da entrevista semiestruturada, aliadas ao estudo de caso (GIL, 2010). Esta pesquisa assim se caracteriza, pois estuda o caso específico da Prefeitura de Santa Maria/Rs, sendo justificada pelo fato de, no ano de 2014, o Tribunal de Contas do Rs certificou o município como um dos entes públicos gaúchos que melhor atenderam as normas de transparência no Estado.

De acordo com o Instituto Brasileiro de Geografia e Estatística (IBGE), a Cidade de Santa Maria/Rs está localizada a $293 \mathrm{~km}$ de Porto Alegre, capital do estado, com uma população estimada em 2014 de 274.838 habitantes, sendo considerada uma cidade de médio porte, figurando como a $5^{\text {a }}$ cidade mais populosa do Rs e a maior da sua região. Estima-se que no ano de 2014 a população do Rs era de 11.207.274 habitantes, distribuídos entre 497 municípios. As 5 (cinco) cidades com maior população concentram 2.899.575 habitantes, representando, aproximadamente, $26 \%$ da população total do estado.

Conhecida como "cidade universitária", a cidade estudada possui diversas instituições de ensino superior, incluindo a Universidade Federal de Santa Maria (UfSM). Conforme as informações disponibiliza- 
das no Portal de Transparência, a Prefeitura de Santa Maria, até o ano de 2015, possuía 3.433 servidores públicos, divididos entre celetistas, cargos de confiança e estatutários, sendo permitido a este o uso de diárias e passagens, conforme as finalidades e condições estabelecidas para sua concessão.

Inicialmente, foram apurados os gastos com diárias e passagens e sua representatividade no orçamento de 2014, através da análise vertical, verificando seu comportamento. As informações orçamentárias foram extraídas dos relatórios contábeis disponibilizados na internet pelo Portal da Transparência. Na sequência, os dados relativos à legislação foram coletados em documentos oficiais, como Leis, Decretos e Instrução Normativa que instituíram regras a serem observadas no processo de concessão de diárias e passagens do ente público estudado, os quais são produzidos e recebidos pelos órgãos da administração pública. A partir deste ponto, observaram-se os procedimentos adotados para o controle interno dos gastos com diárias e passagens. Os dados foram coletados junto à Controladoria e Auditoria Geral do Município (CAGEM), por meio de entrevista semiestruturada com a Superintendência do setor, que esclareceu os procedimentos seguidos pela entidade na concessão dessa despesa e o papel fiscalizador do controle interno.

Por fim, para apurar a representatividade das despesas com diárias e passagens em relação à receita realizada no exercício de 2014 foi utilizada a análise vertical. Além disso, foi traçado um comparativo entre os 5 (cinco) municípios identificados com a maior população do Rs, conforme dados do Instituto Brasileiro de Geografia e Estatística (IBGE, 2014).

\section{RESULTADOS E DISCUSSÕES}

De acordo com os dados coletados, foram identificados 2.382 processos de diárias concedidas no ano de 2014, atendendo 296 servidores diferentes $(8,62 \%)$, sendo emitidos os respectivos empenhos para execução da despesa, cujos processos estão sujeitos à fiscalização do controle interno e externo. Dentre os destinos solicitados, identificam-se diversas localidades, sendo a maior parte das viagens realizadas dentro do estado gaucho (90,85\%), com Porto Alegre/Rs sendo o destino mais frequente $(33,17 \%)$. Dentre as finalidades justificadas nos processos, a maior representatividade foi o transporte de pacientes (59,52\%), seguido da participação de cursos de capacitação, eventos e treinamentos $(14,40 \%)$, demais atividades relacionadas com o exercício profissional $(12,16 \%)$, transporte de servidores $(9,44 \%)$, participação em reunião com outros entes públicos $(2,94 \%)$ e visitação técnica ( $1,54 \%)$. Na sequência é apresentado como é autorizado o gasto e o processo de controle interno, conforme descrito em normativas institucionalizadas no município. 
PROCESSO DE CONCESSÃO DE DIÁRIAS E PASSAGENS

Para identificar os procedimentos institucionalizados para concessão de diárias e passagens aos agentes públicos no município estudado, foi aplicada uma entrevista junto à responsável pela Superintendência de Controle Interno (Controladoria e Auditoria Geral do Município), que relatou as legislações vigentes utilizadas, conforme demonstra O QUADRO 1.

QUADRO 1 - Legislação adotada nas diárias e passagens.

\begin{tabular}{|c|c|}
\hline LEGISLAÇÃO & ESPECIFICAÇÃO \\
\hline Lei Ordinária (LO) nº 3.296 de o8/о1/1991 & $\begin{array}{l}\text { Fixa o valor básico e estabelece } \\
\text { índices para efeito de cálculo } \\
\text { das diárias concedidas aos } \\
\text { servidores públicos municipais } \\
\text { e dá outras providências. }\end{array}$ \\
\hline $\begin{array}{l}\text { Lei ordinária (LO) no } 3.326 \text { de o4/o6/1991 - } \\
\text { Dispõe sobre o Regime Jurídico Único dos } \\
\text { Servidores Públicos Municipais (RJU). }\end{array}$ & Art. 77 - Diárias e Passagens. \\
\hline $\begin{array}{l}\text { Decreto Executivo (DE) no } 005 \\
\text { de 12/o1/2011 - Dispõe sobre autorização } \\
\text { de viagens, concessão de diárias } \\
\text { e prestação de serviço extraordinário, } \\
\text { no âmbito do Poder Executivo Municipal. }\end{array}$ & $\begin{array}{l}\text { Estabelece o valor das diárias, } \\
\text { bem como, relata que apenas } \\
\text { o (a) secretário (a) da pasta pode } \\
\text { propor diárias ou seu substituto } \\
\text { legal, limitando a dois o número } \\
\text { participantes em eventos (cursos, } \\
\text { treinamentos, entre outros), salvo } \\
\text { autorização expressa do Prefeito. }\end{array}$ \\
\hline $\begin{array}{l}\text { Instrução Normativa (IN) nº } 001 \\
\text { de 21/01/2015 - Dispõe sobre requisitos } \\
\text { e procedimentos para concessão } \\
\text { e prestação de contas das diárias } \\
\text { e passagens no Município de Santa Maria. }\end{array}$ & $\begin{array}{l}\text { Relaciona um fluxograma } \\
\text { descrevendo os procedimentos } \\
\text { necessários, bem como as datas } \\
\text { que cada setor tem para processar } \\
\text { a concessão de diárias e passagens. }\end{array}$ \\
\hline
\end{tabular}

FONTE: Dados da pesquisa (2016).

A Lei n 3.296/1991 estabelece que os valores das diárias sejam obtidos mediante os índices especificados no QUADRO 2. Se o valor resultante do cálculo for fracionado, será arredondado para maior. Além disso, ao servidor público que exerce função gratificada, é devido o valor de maior índice entre o cargo e a função por ele ocupada.

Por outro lado, a Lei 3.326/1991 dispõe que receberá a diária o servidor que por determinação da autoridade competente, deslocar-se eventual ou transitoriamente para fora do município, no desempenho de suas funções, em missão ou estudo de interesse da administração. A ele será concedida o valor do transporte e diária para cobrir as despesas de alimentação, estadia e locomoção urbana. Caso o período de afastamento seja inferior a 12 horas, o servidor receberá somente a metade do valor da diária. As viagens à capital do Estado ou para fora são multiplicadas pelo valor de referência para o cargo, por 1,5 e 2,5, respectivamente. $\mathrm{O}$ QUADRO 2 apresenta os índices. 
QUADRO 2 - Índices para o cálculo das diárias.

\begin{tabular}{|c|c|c|c|c|}
\hline \multirow{3}{*}{ 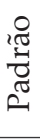 } & I e II & \multirow{3}{*}{$\frac{\mathscr{U}}{\mathscr{\sigma}}$} & \multicolumn{2}{|r|}{1,00} \\
\hline & III e IV & & \multicolumn{2}{|r|}{1,25} \\
\hline & V, vi e viI & & \multicolumn{2}{|r|}{1,50} \\
\hline \multicolumn{5}{|c|}{ II - PLANO DE CARREIRA } \\
\hline \multirow{4}{*}{$\begin{array}{l}\mathbb{Z} \\
\mathbb{Z} \\
\tilde{\sigma} \\
\tilde{\sigma}\end{array}$} & QUADRO EM EXTINÇÃO: NÍVEL E & \multirow{4}{*}{ : } & NÍveL & QUADRO DO MAGISTÉRIO \\
\hline & 1 e 2 & & - & $1, \mathrm{OO}$ \\
\hline & 3 e 4 & & 1 e 2 & 1,25 \\
\hline & 5 e 6 & & 3 e 4 & 1,50 \\
\hline \multicolumn{5}{|c|}{ III - QUADRO DE CARGOS EM COMISSÃO E FUNÇÕES GRATIFICADAS } \\
\hline \multirow{4}{*}{ 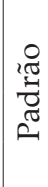 } & 1 e 2 & \multirow{4}{*}{ 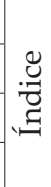 } & \multicolumn{2}{|r|}{$1, \mathrm{OO}$} \\
\hline & 3 e 4 & & \multicolumn{2}{|r|}{1,25} \\
\hline & 5,6 e 7 & & \multicolumn{2}{|r|}{1,50} \\
\hline & 8 & & \multicolumn{2}{|r|}{1,75} \\
\hline
\end{tabular}

FONTE: Adaptado do Anexo da Lei Ordinária nº 3.296/1991.

Consta na Lei n⿳o 3.326/1991 que se o deslocamento do servidor constituir exigência permanente do cargo, não terá direito a diária. Mas, se receber diárias e não se afastar do município, por qualquer motivo, fica obrigado a restituí-las integralmente, no prazo de 03 (três) dias, assim como se retornar antes do previsto, restituirá as diárias recebidas em excesso. A lei estabelece que os servidores que participam de grupos de trabalho, em missão no interior do município, terão direito a $20 \%$ (vinte por cento) do valor da diária, quando necessário pernoite, e 10\% (dez por cento) quando não for exigido pernoite.

Conforme dispõe o $\mathrm{DE} \mathrm{n}^{\mathrm{o}}$ 005/2011, a concessão de diárias aos servidores do Poder Executivo, exceto Secretários de Município e Presidente de Entidades da Administração Indireta, deverão observar que as viagens para fora do Estado devem ser autorizadas pelo Prefeito; devem atender a uma finalidade pública, descrita no requerimento; e, quando da participação em eventos, fica limitado ao máximo de dois servidores, salvo autorização expressa do Prefeito (SANTA MARIA, RS, 2011). De acordo com o decreto, o valor básico das diárias está fixado em $\mathrm{R} \$ 113,15$ (cento e treze reais e quinze centavos). Contudo, os valores são apurados pela aplicação dos índices (QUADRO 2) sobre o valor fixado no DE.

Identificado como calcular o valor da diária, buscou-se entender O PCDP, através de entrevista com a superintendente do controle interno, que explicou o processo, ressaltando que o Secretário da pasta de origem do servidor que requer a diária é quem faz o encaminhamento do pedido, seguindo-se o tramite, conforme as normativas instituídas no município. A partir dos dados coletados na entrevista, combinados com as informações extraídas das normativas institucionalizadas no município, propõem-se a adoção de um fluxograma que representa o processo, como um todo. Apresenta-se na FIGURA 1, o Fluxograma proposto e validado pelo órgão de controle interno. 
Conforme verificado, as solicitações devem ser enviadas à Secretaria de Município de Gestão e Modernização Administrativa (SMG), com antecedência mínima de o6 (seis) dias úteis da data da viagem, mediante o documento denominado Proposta e Concessão de Diárias e/ou Passagens. O servidor solicita a viagem e o Secretário da pasta autoriza ou não. Em caso negativo, o processo não prossegue, mas se autorizado, é solicitado ao gerente administrativo que verifica a existência de dotação para a despesa. Após, a solicitação é enviada à SMG que verifica os requisitos presentes no DE 005/2011 e na IN 001/2015, retornando à secretaria de origem se incorretas. Caso esteja correto, são calculados os valores das diárias e passagens, tendo o prazo de 02 (dois) dias úteis após o recebimento da mesma, e as solicitações são enviadas para o ordenador de despesa (Secretário de Finanças) que autoriza ou não.

Figura 1 - Fluxograma do Processo de concessão de diárias e passagens em Santa Maria/RS

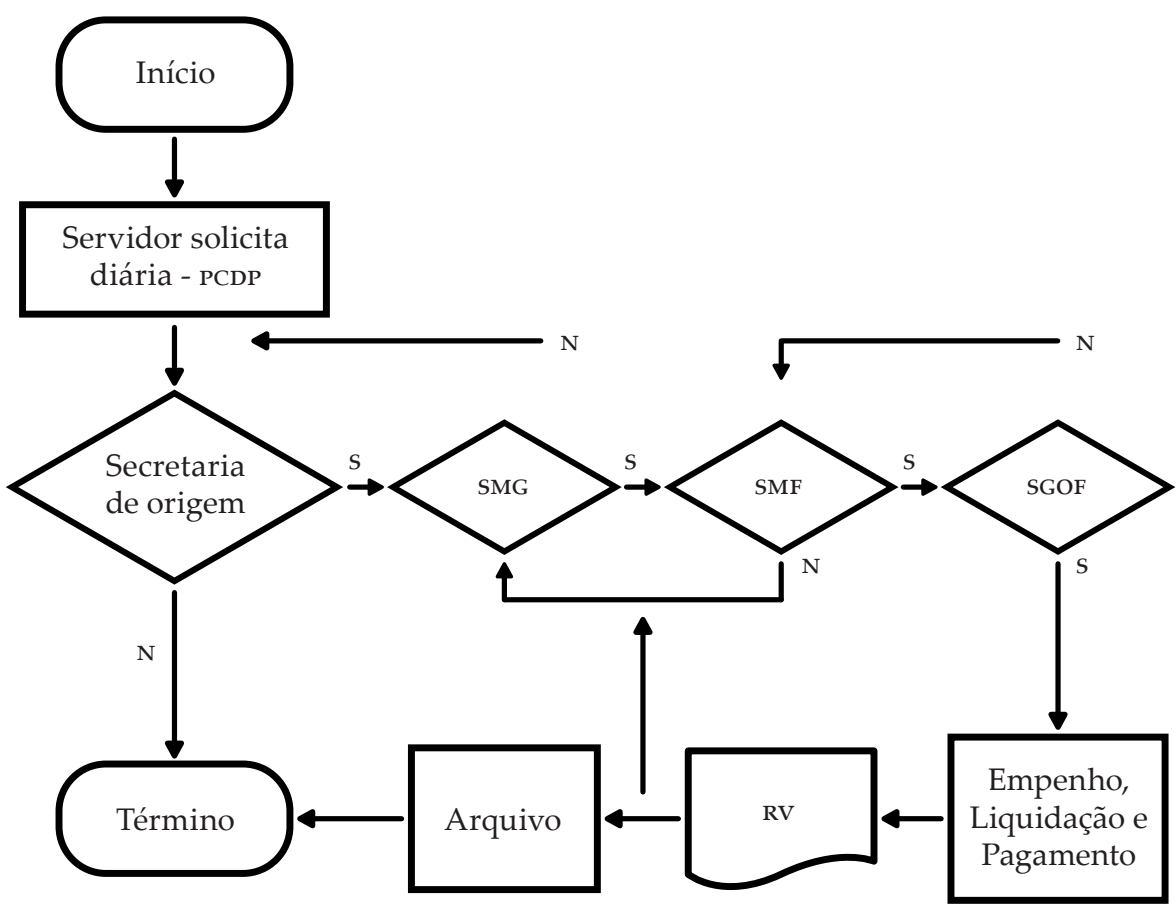

FONTE: Dados da pesquisa (2016).

Depois de recebidas pela Secretaria Municipal de Finanças (SMF), se não autorizadas, retornam à SMG para devolução ao solicitante. No entanto, as solicitações de diárias e passagens autorizadas são encaminhadas à Superintendência de Gestão Orçamentária e Financeira (SGOF) para continuidade dos procedimentos contábeis e orçamentários, sendo emitidos os empenhos para liquidação e pagamento. Para isso, a SMF tem prazo de o1 (um) dia útil para análise do pedido. Depois de recepcionado pela SGOF, tem-se o prazo de 03 (três) dias úteis para execução da despesa, aguardando os documentos de comprovação para a prestação de contas pelo beneficiário do recebimento do recurso. 
Ao receber o Relatório de Viagem (Rv), a sGof confere todos os documentos anexos ao processo, no intuito de averiguar se todos os requisitos foram preenchidos. Se as solicitações de diárias e/ou passagens estão de acordo com os dados constantes no RV, o mesmo é encaminhado para arquivamento. Caso haja diferenças entre as solicitações de diárias e/ou passagens que geraram o empenho, liquidação e pagamento e as informações que conste no RV, encaminha-se à SMG para que seja calculado o valor complementar ou o desconto em folha, conforme o caso. A não apresentação do RV no prazo estabelecido implica no desconto em folha de pagamento do valor pago pela diária não comprovada. Caso essa diária não tenha sido paga, o seu empenho será estornado. Havendo algum erro formal no Rv, o mesmo retorna a secretaria de origem para correções, e posteriormente retorna à SGOF, quando correto. Por fim, os processos concluídos são encaminhados ao arquivo e ficam disponíveis para o controle interno realizar a fiscalização.

As solicitações de diárias e passagens para participação em eventos de capacitação, cursos e treinamentos devem ser acompanhadas da sua programação oficial. Nos demais casos, as solicitações deverão estar acompanhadas da agenda de compromissos, mostrando data e horário dos mesmos, órgãos e entidades a serem visitados, bem como os assuntos em pauta. Após retornar, o servidor tem o prazo máximo de 03 (três) dias úteis para apresentar o RV à SGOF. Nesse relatório deverão constar os assuntos tratados e os resultados obtidos com a viagem realizada, notas fiscais que comprove gastos realizados na cidade de destino, bem como cópia do certificado de participação no curso e/ou atestado de frequência, se for o caso.

Se o servidor recebeu valores de passagens de ônibus deverá apresentar o comprovante original da passagem. Mas, se o deslocamento ocorrer em veículo próprio, será realizado o ressarcimento do combustível, limitado ao valor da passagem padrão com seguro, devendo constar na prestação de contas a nota fiscal que comprove o gasto com combustível, compatível com a viagem, apresentando a Solicitação de Ressarcimento de Combustível. Destaca-se que os servidores cedidos ou conselheiros não recebem diária, mas podem receber passagens, se for necessário. Caso tenha cumprido o solicitado, o servidor é dispensado de devolver o valor que sobrou do pagamento das diárias, já que não é obrigatório comprovar os gastos totais, sendo que os gastos com a alimentação, transportes e hospedagem, não precisam ser exatamente iguais ao valor recebido, pois não se trata de ressarcimento de despesa, mas sim uma indenização. Porém, se as passagens solicitadas não foram utilizadas ou foram extraviadas, não havendo como comprovar seu uso, o valor deve ser devolvido.

O valor pago de diárias e passagens é um rendimento isento e não é realizado via folha de pagamento e sim em depósito direto na conta bancária do servidor. Geralmente, as passagens são adquiridas diretamente na rodoviária ou agências de turismo. Observa-se que a passagem será concedida somente se o deslocamento não ocorrer com 
veículo oficial do ente, ou ainda, se a mesma não for paga pela instituição que promoveu o evento. Destaca-se que o transporte com veículo oficial somente será utilizado pelo Prefeito, Vice-Prefeito, Secretários, por mais de dois servidores em viagem, servidor encaminhado pelo Secretário da pasta ou em situações específicas, como é o caso de coleta de sangue em cidades vizinhas para o banco de sangue municipal.

No caso dos procedimentos para concessão de diárias e passagens e controles exercidos no ambiente interno do contexto público municipal, percebe-se a existência de mecanismos de isomorfismo institucional, cujos componentes regulatórios e normativos exprimem a legitimidade dos atos praticados, amparados em normativas institucionalizadas para o exercício funcional e a regularidade perante os órgãos de fiscalização e sociedade.

\section{CHECKLIST DE DOCUMENTOS E PENALIDADES NA PRESTAÇÃO DE CONTAS}

Em conformidade ao exposto pela IN 001/2015, o ente público tem que cumprir determinados procedimentos para conceder e pagar diárias e passagens e os servidores deverão prestar contas dos gastos, por meio da apresentação de documentos que justifiquem o valor e o local, bem como os bilhetes de passagens, após o retorno da viagem. Se a viagem não for realizada ou se a mesma ocorrer em tempo menor do que o previsto, ou ainda se as passagens não forem utilizadas, as mesmas devem ser devolvidas no prazo máximo de 03 (três) dias úteis à SGOF. A não prestação de contas ou apresentação de forma incompleta impossibilitará a concessão de novas diárias/passagens, até que seja regularizada a pendência.

Em relação à prestação de contas, a IN $n^{0}$ 001/2015 estabelece que se não for apresentado o RV no prazo de 03 (três) dias úteis ou haja divergência entre a solicitação e o relatório, se o pagamento foi realizado a menor, far-se-á empenho e pagamento complementar, mas se o valor pago foi maior, o mesmo deve ser ressarcido por meio de desconto na folha de pagamento do servidor, já autorizado no próprio formulário de Proposta e Concessão de Diárias e/ou Passagens. Dessa forma, à penalização pela não prestação de contas prevê a devolução de valores e a possibilidade de abertura de sindicância ou Processo Administrativo Disciplinar (PAD), em descumprimento de obrigação funcional.

Dessa forma, observa-se um checklist de documentos elaborado pelo setor de controle interno para fiscalização dos processos, onde se observa: comprovantes de despesas (gastos com alimentação, hospedagem, comprovante de deslocamento na cidade de destino, entre outros), constando a data e local da viagem, condizente com o solicitado; comprovantes de passagens aéreas/rodoviárias, ou, comprovantes de aquisição de combustível (caso tenha viajado com veículo próprio); certificado de participação em curso, palestra, congresso, seminário, encontro ou seu atestado de frequência; além disso, os motoristas de veículos oficiais, quando em viagem a trabalho, devem utilizar o 
formulário "Comprovante de Deslocamento", o qual consta sua identificação, data e o horário de saída e retorno, bem como atestado que compareceu ao local, cumprindo o motivo do deslocamento. Nos casos em que não seja possível a assinatura e carimbo no local de destino, o titular da secretaria para a qual o serviço foi prestado poderá emitir "Atestado de Deslocamento", confirmando a realização da viagem.

Do total de processos de diárias e passagens que originaram os empenhos, liquidação e pagamentos no ano de 2014 em Santa Maria (2.382), 104 apresentaram alguma inconsistência (4,37\%), sendo apontado como as mais frequentes a falta de comprovação de despesas nos relatórios de viagens; horários de saída e retorno divergentes do solicitado e cancelamento de eventos. Tais situações ocorridas penalizam o servidor com a devolução do recurso recebido, por meio de desconto em folha de pagamento, o que totalizou uma devolução de R \$21.401,41 aos cofres públicos do município, sendo estornados os respectivos empenhos.

\section{REPRESENTATIVIDADE DOS GASTOS COM DIÁRIAS E PASSAGENS}

O orçamento público de Santa Maria/Rs do ano de 2014 previa uma receita total de $\mathrm{R} \$$ 530.000.000, O0, sendo realizado $\mathrm{R} \$$ 521.041.701,75 (98,31\% do previsto). Dessa arrecadação, $\mathrm{R} \$ 465.833 .202,56$ são receitas correntes $(89,40 \%$ do total arrecadado). No período, os gastos com diárias e passagens foram fixados em $\mathrm{R} \$ 675.000,00$, cuja execução totalizou $\mathrm{R} \$ 643 \cdot 540,07$. Apresenta-se na Tabela 1 os valores, representatividade e variação.

TABELA 1 - Gastos com diárias e passagens.

\begin{tabular}{|l|r|r|r|r|r|}
\hline \multicolumn{1}{|c|}{2014} & \multicolumn{2}{|c|}{ PREVISTO } & \multicolumn{2}{c|}{ REALIZADO } & VARIAÇÃO \\
\hline SANTA MARIA & $\mathrm{R} \$$ & AV $(\%)$ & $\mathrm{R} \$$ & AV $(\%)$ & AH $(\%)$ \\
\hline RECEITA TOTAL & $530.000 .000,00$ & 100,00 & $521.041 .701,75$ & 100,00 & 98,31 \\
\hline RECEITA CORRENTE & $402.871 .000,00$ & 76,01 & $465.833 .202,56$ & 89,40 & 115,63 \\
\hline DIÁRIAS & $575.000,00$ & 0,11 & $558.777,74$ & 0,11 & 97,18 \\
\hline PASSAGENS & $100.000,00$ & 0,02 & $84.762,33$ & 0,02 & 84,76 \\
\hline
\end{tabular}

FONTE: Dados da pesquisa (2016).

Os dados apresentados na TABELA 1 demonstram que os valores executados de diárias e passagens absorveram 0,13\% do total arrecadado no Município em 2014. A comparação desses gastos com a receita corrente arrecadada (maior em $15 \%$ do que a prevista) demonstra que $0,13 \%$ foram aplicados em diárias e passagens. Assim, esses gastos possuem pouca representatividade quando comparados às receitas totais, porém são valores relativamente altos e se deve analisar os benefícios gerados e os serviços públicos diretamente impactados. Conforme os dados analisados, grande parte dos gastos com diárias e passagens no período refere-se ao transporte de pacientes da Secretaria de Saúde para diferentes localidades, além de cursos de capacitação a servidores, em especial da SMG e da SMF. 
Para verificar se o gasto identificado é compatível com a realidade do ente estudado, realizou-se um comparativo com outros municípios. De acordo com os dados do IBge (2014), os o5 (cinco) Municípios do estado gaúcho com maior população são apresentados na TABELA 2, com o quantitativo da população estimada, receita líquida arrecadada (receita total, deduzidos os repasses à previdência) e os valores gastos com diárias e passagens.

TABELA 2 - Municípios com maior população no RS em 2014.

\begin{tabular}{|l|r|r|r|r|r|}
\hline \multirow{2}{*}{ MUNICÍPIOS } & \multicolumn{5}{|c|}{2014} \\
\cline { 2 - 6 } & POPULAÇÃO & \multicolumn{1}{|c|}{ RECEITA LÍQUIDA } & \multicolumn{1}{c|}{ PASSAGENS } & \multicolumn{1}{c|}{ DIÁRIAS } & \% \\
\hline $\begin{array}{l}\text { PORTO } \\
\text { ALEGRE }\end{array}$ & 1.472 .482 & $5.217 .955 .841,07$ & $1.739 .115,65$ & $543.218,50$ & 0,0437 \\
\hline CAXIAS & 470.223 & $1.132 .583 .814,96$ & $373.142,57$ & $622.206,43$ & 0,0879 \\
\hline PELOTAS & 342.053 & $538.280 .452,20$ & $395.398,90$ & $506.619,61$ & 0,1675 \\
\hline CANOAS & 339.979 & $1.108 .926 .421,12$ & $635.854,95$ & $265.955,53$ & 0,0813 \\
\hline $\begin{array}{l}\text { SANTA } \\
\text { MARIA }\end{array}$ & 274.838 & $408.114 .603,74$ & $84.762,33$ & $558.777,74$ & 0,1577 \\
\hline
\end{tabular}

FONTE: Dados Extraídos do Controle Social - Tribunal de Contas do Estado (TCE/RS, 2015).

Os dados apresentados na TABELA 2 referem-se à população estimada (IBGE, 2014), dos 05 (cinco) municípios com maior população no RS, evidenciando-se os valores relativos à Receita Líquida (extraídos do balancete da receita de 2014) e os valores liquidados nos elementos de despesa 3.3.90.14 (Diárias), 3.3.90.33.01 (Passagens no país) e 3.3.90.33.02 (Passagens para o exterior) foram coletados no site do TCE/ RS, destinado ao controle social. Para traçar o percentual de representação destes gastos em relação à receita líquida, verifica-se que a cidade de Pelotas apresenta a maior representatividade de gastos dentre os municípios comparados, enquanto Porto Alegre tem os menores gastos nessa despesa.

Para comparar os valores gastos com diárias e passagens em cada município, foram calculados os gastos proporcionalmente por habitante, dividindo-se a soma dessas despesas pelo total da população da cidade. Os resultados demonstram que o município com maior gasto com diárias e passagens por habitante em 2014, dentre aqueles analisados, é Canoas, com R \$2,65. Já Porto Alegre apresenta o menor gasto por habitante no período, $\mathrm{R} \$ 1,55$, podendo ser explicado por ser a capital do estado e onde acontece a maior parte dos cursos e eventos, além de sediar os principais órgãos públicos relacionados. A TABELA 3 apresenta esses resultados. 
TABela 3 - Gastos com Diárias e Passagens por habitante

\begin{tabular}{|l|r|r|r|}
\hline \multirow{2}{*}{ MUNICÍPIOS } & \multicolumn{3}{|c|}{2014} \\
\cline { 2 - 4 } & POPULAÇÃO & $\begin{array}{r}\text { TOTAL DE DIÁRIAS } \\
\text { E PASSAGENS (R\$) }\end{array}$ & $\begin{array}{c}\text { GASTO POR } \\
\text { HABITANTE (R\$) }\end{array}$ \\
\hline PORTO ALEGRE & 1.472 .482 & $2.282 .334,15$ & 1,55 \\
\hline CAXIAS & 470.223 & $995.349,00$ & 2,12 \\
\hline PELOTAS & 342.053 & $902.018,51$ & 2,64 \\
\hline CANOAS & 339.979 & $901.810,48$ & 2,65 \\
\hline SANTA MARIA & 274.838 & $643.540,07$ & 2,34 \\
\hline
\end{tabular}

FONTE: Dados da pesquisa (2016).

Em contraponto, Santa Maria apresenta gasto com diárias e passagens de R\$2,34 por habitante no período analisado, podendo ser justificado por ser o município mais distante da capital, o que demonstra um gasto proporcional aos demais municípios analisados, considerando que Canoas, por exemplo, é a cidade mais próxima de Porto Alegre e apresenta gastos mais elevados nessa despesa.

\section{CONTROLE INTERNO NA GESTÃO PÚBLICA}

No Município de Santa Maria/Rs, conforme a L.o. ํㅡㄴ 4.409/2001, o controle interno é desempenhado pela Diretoria de Controle Interno, devendo ser exercido em todos os níveis e qualquer escalão administrativo, bem como acompanhar e assessorar os agentes na execução de suas funções; em todas as unidades do Poder Executivo e a qualquer tempo. Em conformidade com a L.o. nº 5.849/2014, o Sistema de Controle Interno (sCI) tem a finalidade de requerer a fiscalização contábil, financeira, orçamentária, operacional e patrimonial, quanto aos princípios constitucionais da legalidade, legitimidade, economicidade, eficiência e moralidade na gestão dos recursos, bem como avaliar os resultados alcançados. Além disso, o art. $2^{\underline{0}}$ diz que o Controle Interno é compreendido como o conjunto de processos adotados pelas próprias gerências do setor público, com o intuito de impedir erros, fraudes e ineficiência, visando atender princípios constitucionais. Já a Superintendência Central de Controle Interno (SCCI) é o órgão responsável pela coordenação das atividades do sistema de controle interno.

Segundo o art. $3^{\text {o }}$ e o $\S 1^{\circ}$ do art. 13 da Lei 5.849/2014, estabelecem que o SCCI visa à avaliação e controle da ação governamental e da gestão fiscal dos administradores municipais, mediante fiscalização dos métodos e medidas adotados pela Administração para salvaguardar ativos, desenvolver a eficiência nas operações, avaliar o cumprimento dos programas, objetivos, metas e orçamentos e políticas administrativas prescritas. Além disso, ao ter ciência de qualquer irregularidade, a SCCI 
comunicará o fato ao Prefeito, ao Presidente da Câmara de Vereadores, ao Controlador Geral do Município e, no caso de não ser sanada a falha, ao Tribunal de Contas do Estado e ao Ministério Público, sob pena de responsabilidade solidária.

Conforme o art. 13 da Lei 5.849/2014 está mencionado que compete a SCCI algumas funções, como: coordenar as atividades relacionadas ao scı do Município, fixar prazos a serem cumpridos pelos órgãos e entidades auditados internamente para resposta aos questionamentos formulados e aos relatórios elaborados, assim como adotar medidas corretivas; apoiar o controle externo; medir e avaliar a eficiência e eficácia dos procedimentos de controle interno adotados pelos Órgãos Setoriais do Sistema, através da atividade de auditoria interna; exercer o acompanhamento sobre o cumprimento das metas fiscais e sobre a observância aos limites e condições impostas pela LC nํํำ1/2000; manifestar-se, quando solicitado pela Administração, e em conjunto com a Procuradoria Geral do Município, acerca da regularidade de processos licitatórios, sua dispensa ou inexigibilidade, e cumprimento e/ou legalidade de atos e contratos; orientar o estabelecimento de mecanismos voltados a comprovar a legalidade e a legitimidade dos atos de gestão e avaliar os resultados, quanto à eficácia, eficiência e economicidade na gestão orçamentária, financeira e patrimonial das entidades públicas municipais, bem como na aplicação de recursos públicos por entidades de direito privado; entre outras.

De acordo com as informações coletadas na entrevista, as analisadas realizadas pelo Controle Interno ocorrem por meio de controles prévios, na medida em que a sccı auxilia na elaboração de normativas, formulários e fluxos para melhor controle da tramitação do processo, desde a solicitação de diária/passagem até a prestação de contas. Ainda, são realizados controles concomitantes, verificando diárias e passagens concedidas e a tramitação dos processos, quando necessário, por meio da verificação amostral aleatória. A atuação do controle interno é realizada via solicitação e verificação dos processos nas auditorias in loco realizadas no município, além do acompanhamento e possíveis denúncias à ouvidoria do TCE/RS.

\section{CONSIDERAÇÕES FINAIS}

Com objetivo de analisar os gastos com diárias e passagens na esfera municipal, considerando que há necessidade da participação da sociedade no controle e fiscalização da aplicação dos recursos públicos, desenvolveu-se esta pesquisa, buscando identificar os procedimentos para concessão de diárias e passagens, sua representatividade frente ao orçamento e os procedimentos de controle interno adotados.

Com relação à legislação, observou-se que o município estudado segue normativas específicas institucionalizadas, enquanto os procedimentos para concessão e controle de diárias e passagens seguem normativas operacionalizadas de forma manual e utilizando formulários em papel, exigindo seu trâmite entre os setores envolvidos, demandan- 
do mais tempo e serviços, tornando o processo ainda mais burocrático. No que se refere ao controle interno, este setor exerce a função de normatização e realiza a fiscalização nas solicitações de diárias e de passagens, dentre outras funções. Ao examinar os processos de diárias e passagens, o controle interno busca investigar o motivo do gasto e o interesse público, evitando assim, a má aplicação de recursos públicos.

Os gastos com diárias e passagens do município, no ano de 2014, representam $0,13 \%$ da receita arrecadada no exercício, portanto, observa-se que os gastos com esse tipo de despesa apresentam pouca expressividade frente aos valores totais. Contudo, tratando-se de recursos públicos, sendo os mesmos controlados com procedimentos definidos de forma normativa para evitar fraudes. Depois de identificados os O5 (cinco) municípios com maior população no Rs, foram apurados os percentuais de representação do gasto com diárias e passagens em relação à receita líquida e a proporcionalidade do gasto por habitante. Os resultados demonstram que o município com maiores gastos de diárias e passagens por habitante, dentre os analisados, é Canoas, ( $\$ \$ 2,65)$, enquanto Porto Alegre apresenta o menor gasto por habitante $(\mathrm{R} \$ 1,55)$.

De forma geral, constata-se que os objetivos propostos neste estudo foram alcançados à medida que foi possível conhecer como se desenvolvem os processos para concessão de diárias e passagens na esfera municipal, bem como, sua representatividade em relação ao respectivo orçamento. A maneira complexa e minuciosa relatada na entrevista demonstra o zelo e a atenção expedida pelos envolvidos no processo. Desta forma, entende-se que a pesquisa pode contribuir com outros entes públicos municipais, servidores e demais entidades de fiscalização, instrumentalizando e demonstrando as práticas realizadas no âmbito municipal, além de estruturar o processo de concessão e controle de gastos com diárias e passagens de forma empírica.

Algumas limitações foram observadas no desenvolvimento do trabalho, como a inexistência de dados estatísticos do setor de controle interno e elementos comparativos estabelecidos pelo TCE, restringindo-se a pesquisa aos aspectos comparativos no âmbito orçamentário. Desta forma, para futuros estudos, sugere-se a verificação dos procedimentos relacionados à concessão e controle das despesas com diárias e passagens em comparação com outros municípios, além de estender a análise temporal da despesa, com o intuito de traçar o comportamento no longo do tempo.

\section{REFERÊNCIAS}

AGÊNCIA DE DESENVOLVIMENTO DE SANTA MARIA. Santa Maria em Dados. Município de Santa Maria, 2014. Disp. http://santamariaemdados.com.br/1-aspectos-gerais. 
ALBUQUERQUE, C. M.; MEDEIROS, M.; FEIJÓ, P. H. Gestão de finanças públicas: Fundamentos e práticas de planejamento, orçamento e administração financeira com responsabilidade fiscal. Gestão Pública Editora, 2ed, Brasília, 2008.

ANDRADE, N. D. A. Contabilidade pública na gestão municipal: métodos com base nas normas brasileiras de contabilidade aplicadas ao setor público (NBCASP) e nos padrões internacionais de contabilidade. São Paulo: Atlas, 2012.

BOTELHO, M. M. Manual de Controle Interno: teoria \& prática. Ed. Juruá, 2005

BRASIL. Lei $\mathrm{n}^{\mathrm{o}}$ 12.527, de 18 de novembro de 2011. Regula o acesso a informações previsto no inciso XXXIII do art. $5^{\circ}$, no inciso II do $\$ 3^{\circ}$ do art. 37 e no $\S 2^{\circ}$ do art. 216 da CF; e dá outras providências. Presidência da República Federativa do Brasil. Disp.: http://www.planalto.gov. br/ccivil_03/_ato2011-2014/2011/lei/112527.htm.

. Lei Complementar n⿳ 101, de o4 de maio de 2000. Estabelece normas de finanças públicas voltadas para a responsabilidade na gestão fiscal e dá outras providências. Presidência da República Federativa do Brasil. Disp.: http://www.planalto.gov.br/ccivil_03/leis/lcp/lcpıo1.htm.

. Lei Complementar n⿳0 131, de 27 de maio de 2009. Acrescenta dispositivos à Lei Complementar n⿳o 101, de 4 de maio de 2000, que estabelece normas de finanças públicas voltadas para a responsabilidade na gestão fiscal e dá outras providências, a fim de determinar a disponibilização, em tempo real, de informações pormenorizadas sobre a execução orçamentária e financeira da União, dos Estados, do Distrito Federal e dos Municípios. Presidência da República Federativa do Brasil. Disp.: http://www.planalto.gov.br/ccivil_03/leis/lcp/lcp131.htm.

. Portaria Interministerial n⿳0 163, de 04 de maio de 2001. Dispõe sobre normas gerais de consolidação das Contas Públicas no âmbito da União, Estados, Distrito Federal e Municípios, e dá outras providências. Secretaria do Tesouro Nacional. Disp.: http://www.tesouro.fazenda.gov.br/hp/downloads/ Portaria_Interm_163_2001_Atualizada_2010_25ag02010.pdf. . Manual de Contabilidade Aplicada ao Setor Público.

Dispõe sobre demonstrações contábeis aplicadas ao setor público. Secretaria do Tesouro Nacional, Brasília, 2014. Disp: http://www.tesouro.fazenda.gov.br/documents/10180/367031/ CPU_MCASP_6edicao/o5eea5ef-a99c-4f65-ao42-077379e59deb. 
CARVALHO, D. Orçamento e Contabilidade

Pública: teoria e prática. Campus, 2007.

CGU. CONTROLADORIA-GERAL DA UNIÃO.

Diárias e passagens. ed. revisada. Brasília: Ascom/

CGU, 2012. Disp.: http://www.cgu.gov.br/publicacoes/

diariaspassagens/arquivos/diariaspassagens.pdf.

DEVARAJAN, S.; SWAROOP, V.; ZOU, H. F. The composition of public expenditure and economic growth. Journal of monetary economics, v37, n2, p 313-344, 1996.

DiMAGGIO, Paul J., POWELL, Walter W. The iron cage revisited: institutional isomorphism and collective rationality in organizational fields. American

Sociological Review, v.48, p.147-160, 1983.

GIAMBIAGI, F.; ALEM, A. C. D. Finanças públicas: teoria e prática no Brasil. Elsevier, 2008.

GIL, A. C. Métodos e técnicas de pesquisa social.

In Métodos e técnicas de pesquisa social. Atlas, 2010.

GRIZOTTI, G. Dinheiro de impostos gastos em viagens.

Jornal Nacional, Rio de Janeiro, 31 jan. 2006. Disp.: http:// jornalnacional.globo.com/Telejornais/JN/o,,MUL565135-10406,o0DINHEIRO+DE+IMPOSTOS+GASTOS+EM+VIAGENS.html.

IBGE. INSTITUTO BRASILEIRO DE GEOGRAFIA E ESTATÍSTICA. Cidades@. Disp.: http://cidades.ibge. gov.br/xtras/perfil.php?lang=\&codmun=431690.

JUNIOR, D. G., JENKINS, L. E. C., ZANIN, D. F., DE ALMEIDA, L. B. O papel da auditoria interna na melhoria da qualidade dos gastos públicos: um estudo exploratório nas IFES do Estado do Paraná. In: Anais do Congresso Brasileiro de Custos-ABC. 2015.

KOHAMA, H. Contabilidade pública: teoria e prática. 7. ed. São Paulo: Atlas, 2000.

MARÇOLA, Célia. Auditoria interna como instrumento de controle social na administração pública. Revista do Serviço Público, v. 62, n. 1, p. 75, 2011.

MARTINS, C. Vereadores de Guaíba passam quatro dias em Brasília para um curso de três horas. Jornal Zero Hora, Porto Alegre, 27 mar. 2009. Disp.: http://zerohora.clicrbs.com.br/rs/ noticia/2009/03/vereadores-de-guaiba-passam-quatro-diasem-brasilia-para-um-curso-de-tres-horas-2455834.html. 
MEYER, John W., ROWAN, Brian. Institutionalized organizations: formal structure as myth and ceremony. American Journal of Sociology, v.83, n.2, p.340-363, 1977.

SCOTT, W. Richard. Organizational

environments: ritual and rationality (updated edition). Newbury Park, Sage, 1992.

MICHEL, M. H. Metodologia e pesquisa em ciências sociais. 2. ed. São Paulo: Atlas, 2009.

NOVAES, C. B.; LASSO, S. V.; MAINARDES, E. W. Percepções do Servidor Público a respeito da Qualidade do Serviço Público. Gestão Pública: Práticas e Desafios, v9, n1, 2016

PETER, M. G. A.; MACHADO, M. V. V. Manual de Auditoria Governamental. 1. ed. 3. São Paulo: Atlas, 2008.

RAUPP, F. M. Gestão de custos no legislativo municipal como instrumento de prestação de contas: Um comparativo entre o custeio por absorção e o custeio baseado em atividades. Cadernos Gestão Pública e Cidadania, v. 16, n. 59, 2011.

RUEF, Martin; SCOTT, W. Richard. A multidimensional model of organizational legitimacy: hospital survival in changing institutional environments. Administrative Science Quarterly, v.43, p. 877-904, 1998.

SAMORA, N. Hartung "esqueceu" de dizer que sua mulher tinha outros motivos para ir para SP e RJ. Jornal Século Diário, Espírito Santo, o9 out. 2014. Caderno Política. Disp.: http:// seculodiario.com.br/19107/8/hartung-esqueceu-de-dizer-quesua-mulher-tinha-outros-motivos-para-ir-para-sp-e-rj-1.

SANTA MARIA. Decreto Executivo nº 005, de 12 de janeiro de 2011. Dispõe sobre autorização de viagens, concessão de diárias e prestação de serviço extraordinário, no âmbito do Poder Executivo Municipal. Município de Santa Maria. Disp.: http:// www.santamaria.rs.gov.br/legisis/detalhes.aspx?Cod=6041.

Instrução Normativa n⿳ำ 001 , de 21 de janeiro 2015. Dispõe sobre os requisitos e procedimentos para a concessão e Prestações de Contas das diárias no Município de Santa Maria. Município de Santa Maria. 2015

Lei Ordinária no 3.296, de o8 de janeiro de 1991. Fixa o valor básico e estabelece índices para efeito de cálculo das diárias concedidas aos servidores públicos municipais e dá outras providências. Município de Santa Maria. 1991. Disp.: http://www.santamaria.rs.gov.br/legisis/detalhes.aspx?Cod=3206. 
SANTA MARIA. Lei Ordinária nº 3.326, de o4 de junho de 1991. Dispõe sobre o Regime Jurídico Único dos Servidores Públicos Municipais e dá outras providências. Município de Santa Maria. 1991. Disp.: http://www. santamaria.rs.gov.br/legisis/detalhes.aspx?Cod=6030.

Lei Ordinária nº 4.409, de 05 de fevereiro de 2001. Cria o sistema de controle interno do Poder Executivo Municipal e dá outras providências. Município de Santa Maria. 2001. Disp.: http://www.santamaria.rs.gov.br/legisis/detalhes.aspx?Cod=4301.

Lei Ordinária $n^{\circ}$ 5.849, de 28 de fevereiro de 2014. Dispõe sobre o Sistema de Controle Interno no Município e dá outras providências. Município de Santa Maria. 2014. Disp.: http://www.santamaria.rs.gov.br/legisis/detalhes.aspx?Cod=6895.

Portal da Transparência. Município de Santa

Maria. 2015. Disp.: http://www.santamaria.rs.gov.br/ docs/transparencia/2015/tqf_20150331-410.pdf.

SCOTT, W. Richard. Introduction: Institutional theory and organizations. In: Scott, W. Richard, SOREN, Christensen. The institutional construction of organizations: international and longitudinal studies. Thousand Oaks: Sage, 1995.

SILVA, L. M. Contabilidade governamental: um enfoque administrativo. Atlas, 2004

SILVA, W. A. C.; GOMES, M. C. O.; ARAÚJO, E. A. T. Controles Internos Determinantes para a Eficiência na Gestão do CEFET/ MG. Revista Contabilidade e Controladoria, n6, v1, 2014

SLOMSKI, V. Manual de contabilidade pública: um enforque na contabilidade municipal, de acordo com a Lei de responsabilidade Fiscal. São Paulo: Atlas, 2008.

SOARES, C. S.; FLORES, S. A. M.; CORONEL, D. A. O Comportamento da Receita Pública Municipal: Um Estudo de Caso no Município de Santa Maria (RS). Desenvolvimento em Questão, v. 12, n. 25, p. 312-338, 2014.

TCE/RS, Tribunal de Contas do Estado do RS. Controle Social. 2015. Disp: http://www1.tce.rs.gov.br/portal/page/portal/tcers. 